\title{
Hubungan Aktifitas Fisik Ibu Hamil Dengan Konstipasi Masa Kehamilan
}

\author{
Siti Mudlikah ${ }^{1)}$; Erda Restiya Agustin²);Ida Susila ${ }^{3)}$ \\ 1) Program Profesi Bidan, Universitas Muhammadiyah Gresik, Gresik 61111, Indonesia \\ 2) Prodi Kebidanan, STIKES Ganesha Husada Kediri, Kediri 12345, Indonesia \\ 3) Prodi Kebidanan, Universitas Islam Lamongan, Lamongan 62211, Indonesia
}

Corresponding Author: Siti Mudlikah

E-mail: mudlikah@umg.ac.id

\section{INFORMASI ARTIKEL}

Riwayat Artikel:

Submit : 25-09-2021

Revisi : 14-10-2021

Diterima : 25-10-2021

Publikasi : 30-11-2021

$\mathrm{DOI}:$

http://dx.doi.org/10.30587/ijmt.v1i1.3320

\section{Keywords:}

Physical activity;

Constipation;

Pregnancy;

Kata Kunci:

Aktivitas fisik;

Konstipasi;

kehamilan;

\begin{abstract}
Constipation occurs in about $11-13 \%$ of pregnancies by symptoms of difficulty on defecating, lower abdominal pain and frequency of passing stools of 3 times a week, causing discomfort and anxiety for pregnant women. The study was to determine the relationship between physical activity and constipation.

The research method is correlation analytic cross sectional approach. Data retrieval is from June to December 2020 at Praktik Mandiri (midwifery services) at Jatikalang Kec. Prambon, Sidoarjo. Population: All 3rd trimester pregnant women totaled 37 people in 2020, or it is called total population sample. Collecting data is by direct questionnaire on statements of light physical activity, moderate physical activity and heavy physical activity. Data analysis uses simple correlation test statistics.

Research results indicate that pregnant women who experience constipation do more light activities are 13 people (100\%, moderate physical activity are of 13 people (92.9\%) than those who are not constipated on heavy physical activity as many as 10 people (100\%), moderate physical activity being 1 person (7.1\%). The results of the statistical test of the correlation between physical activity and constipation in pregnant women have positive value of 0.821 , indicating very strong correlation between physical activity and constipation, significant (2-tailed) $0.00<0.01$, the higher the physical activity of pregnant women, the higher the occurrence of constipation.

Conclusions from this study; There is a strong relationship between physical activity and constipation in pregnant women, namely light physical activity and moderate physical activity less than 30 minutes at risk of constipation. Suggestions for preventing constipation can be done by doing physical activity more than 30 minutes a day, consuming highfiber nutritional diet and drinking enough mineral water to prevent constipation in pregnancy.
\end{abstract}

\section{ABSTRAK}

Konstipasi terjadi sekitar 11-13\% dari kehamilan dengan gejala, sulit buang besar, nyeri perut bawah dan frekuensi buang faeses 3 kali dalam seminggu sehingga membuat ketidak nyamanan dan cemas ibu hamil. Tujuan penelitian untuk mengetahui hubungan antara aktifitas fisik dengan konstipasi.

Metode penelitian analitik korelasi pendekatan Cross Sectional. Pengambilan data bulan Juni sampai Desember Tahun 2020 di Pratik Mandiri bidan Desa Jatikalang Kec. Prambon. Kab. Sidoarjo. Populasi: Semua ibu hamil Trimester 3 berjumlah 37 orang Tahun 2020. Sampel total populasi. Pengambilan data secara kuesioner langsung pada pernyataan 
aktifitas fisik ringan, aktivitas fisik sedang dan aktivitas fisik berat Analisis data menggunakan statistic uji korelasi sederhana.

Hasil penelitian Diketahui ibu hamil yang mengalami konstipasi lebih banyak melakukan aktivitas ringan sejumlah 13 orang $(100 \%$, aktivitas fisik sedang sejumlah 13 orang $(92,9 \%)$ dibandingkan yang tidak konstipati pada aktivitas fisik berat sejumlah 10 orang (100\%), aktifitas fisik sedang sejumlah 1 orang $(7,1 \%)$. Hasil uji statistic korelasi antara aktivitas fisik dengan konstipasi ibu hamil nilai positif 0,821 menunjukkan sangat kuatnya korelasi hubungan antara aktivitas fisik dengan konstipasi significant (2-tailed) $0,00<0,01$ semakin tinggi aktivitas fisik ibu hamil maka makin tinggi terjadi konstipasi.

Simpulan dari penelitian ini Ada hubungan yang kuat antara aktivitas fisik dengan konstipasi ibu hamil yaitu aktivitas fisik ringan dan aktifitas fisik sedang kurang dari 30 menit beresiko terjadi konstipasi. Saran pencegahan konstipasi dapat dilakukan melakukan aktifitas fisik lebih dari $30 \mathrm{~m} 3 \mathrm{nit}$ sehari, mengkonsumsi diet nutrisi tinggi serat dan cukup minum air mineral dapat mencegah terjadinya konstipasi pada kehamilan.

\section{PENDAHULUAN}

Perubahan fisik dan psikologis masa kehamilan terjadi pada semua ibu hamil. Salah satunya gejala yang muncul adalah susah buang air besar atau sembelit. Perubahan fisik masa kehamilan yang sering timbul seperti sering kencing, varises, kaki bengkak, sesak nafas, konstipasi, wasir, aktivitas fisik dan lainnya, sesuai hasil penelitian pola aktivitas terkait dengan terjadinya konstipasi (Hartinah et al., 2019)

Penyebab konstipasi dikarenakan adanya peningkatan hormone progesterone yang mempengaruhi relaksasi otot sehingga kerja percernaan kurang maksimal (Ojieh, 2012). Pembesaran uterus masa kehamilan menekan rahim kebawah menyebabkan menurunnya mobilitas kerja usus dalam mencerna makanan sehingga pembuangan kotoran dalam sistem pencernaan yang membuat sulit buang air besar dan konstipasi (Sembiring, 2017).

Prevalensi ibu hamil mengalami konstipasi berkisar 11-38\% (Trottier et al., 2012). Kontipasi masa kehamilan terjadi pada trimester 1 sejumlah 29,6\%, Trimester 2 sejumlah 19\% dan trimester 3 sejumlah 21,8\% . Konstipasi lebih banyak terpada pad ibu hamil trimester tiga sebab trimester ini produksi hormone progesterone pada puncaknya sehingga memperlambat kerja otot polos pencernaan
(Indah \& Rohmania, 2017). Kontipasi waktu hamil terjadi karena perubahan fungsional yang berkaitan dengan gangguan motilitas anorektal (Preventing or Treating Constipation In, 2008)

Peningkatan hormone progesterone pada awal kehamilan dan akhir kehamilan kurangnya konsumsi serat, kurangnya aktivitas fisik menurunkan kerja usus masa hamil, adanya peningkatan kadar hormone progesterone juga menurunkan peristaltic sistem pencernaan, Kurangnya mengkonsumsi air putih kurang dari 10 gelas sehari, penyakit wasir dan diduka faktor lain seperti konsumsi suplemen zat besi dan kalsium masa kehamilan meningkatkan resiko konstipasi (Trottier et al., 2012). Hasil penelitian penyebab kontipasi ibu hamil yaitu pola makan sejumlah 74\%, Posisi jongkok saat BAB (42\%), olah raga $48 \%$ dan kebiasaan menunda BAB sejumlah (52\%) (Hanim, 2019). Aktivitas fisik diduga sebagai salah satu pemicu terjadinya konstipasi karena aktifitas yang rendah menurunkan gerak peristaltic sehingga memperlambat mekanisme fases menuju rectum dan penyeran cairan yang tinggi menyebabkan feses menjadi kering dan mengeras (Indah \& Rohmania, 2017).

Konstipasi merupakan kondisi susah buang besar dengan frekuensi sekurangkurangnya tiga kali dalam seminggu. Kondisi ini membuat ibu hamil kuatir dan rasa tidak nyaman 
(Widyasari, 2017). Gejala konstipasi biasanya disertai dengan nyeri perut dibagian bawah, perut kembung dan saat buang air besar kotoran keras dan kadang-kadang keluar darah bercampur kotoran. Peningkatan produksi kadar peogresteron pada ibu hamil menyebabkan tonos pada otot polos menurun menyebabkan peristaltic pencernaan lebih lambat sehingga absorsi air pada usus besar meninggat dan fases menjadi lebih keras (Sembiring, 2017).

Studi pendahuluan dipraktik mandiri bidan bulan bulan Januari 2021 dari hasil wawancara $10 \mathrm{ibu}$ hamil pernah mengalami konstipasi sejumlah 7 ibu hamil, rata-rata mengalami BAB 1-2 kali/hari. Dari latarbelakang tersebut peneliti ingin mengetahui persepsi aktifitas fisik dengan konstipasi ibu hamil.

Tujuan penelitian untuk mengetahui hubungan antara aktifitas fisik dengan konstipasi.

\section{METODE}

Desain penelitian analitik korelasi pendekatan Cross Sectional. Pengambilan data bulan Juni sampai Desember Tahun 2020 di Pratik Mandiri bidan Desa Jatikalang Kec. Prambon. Kab. Sidoarjo. Populasi: Semua ibu hamil Trimester 3 berjumlah 37 orang Tahun 2020. Sampel menggunakan total populasi. Pengambilan data umum (gravida dan umur ibu hamil) melalui rekam medic dan data aktivitas fisik dan data konstipasi melalui hasil wawancara langsung dengan responden.

Pengambilan data dilakukan dengan menggunakan kuisioner. Kuesioner aktivitas fisik ibu hamil terdiri dari 8 item tentang pernyataan aktifitas fisik ringan sejumlah 1 poin, aktifitas fisik sedang sejumlah 3 poin dan aktivitas fisik berat sejumlah 5 poin.Variabel independen aktifitas fisik dan variabel dependen yaitu konstipasi ibu hamil.

Analisis data menggunakan uji Statistik korelasi sederhana untuk mengetahui tingkat keeratan hubungan antara variabel bebas aktivitas fisik dan variabel tidak bebas konstipasi.

\section{HASIL PENELITIAN}

\section{Karakteristik Ibu Berdasarkan Gravida}

Tabel 1. Distribusi Frekuensi Gravida Ibu Hamil

\begin{tabular}{lcc}
\hline Gravida & Frekuensi & Prosentase \\
\hline Gravida Pertama & 6 & 16,2 \\
Gravida Dua & 24 & 64,9 \\
Gravida Tiga & 7 & 18,9 \\
\hline Total & 37 & 100 \\
\hline Sul
\end{tabular}

Sumber: data primer, 2020

Berdasarkan tabel 1. Diketahui sebagaian besar ibu hamil gravida dua sejumlah 24 orang $(64,9 \%)$.

\section{Karakteristik Ibu Hamil Berdasarkan Usia}

Tabel 2 Distribusi frekuensi Usia Ibu Hamil

\begin{tabular}{ccc}
\hline Usia Ibu Hamil & Frekuensi & Prosentase \\
\hline$<20$ Tahun & 9 & 24,3 \\
20-30 ahun & 21 & 56,8 \\
$>35$ Tahun & 7 & 18,9 \\
\hline Total & 37 & 100 \\
\hline
\end{tabular}

Sumber: data primer, 2020

Berdasarkan tabel 2. Diketahui sebagaian besar ibu hamil Berusia 20-30 tahun sejumlah 21 orang ( $56,8 \%)$.

\section{Aktivitas Fisik Ibu Hamil}

Tabel 3. Distribusi Frekuensi Aktivitas Fisik Ibu Hamil

\begin{tabular}{lcc}
\hline Aktivitas Fisik & Frekuensi & Prosentase \\
\hline Ringan & 13 & 35,1 \\
Sedang & 14 & 37,8 \\
Berat & 10 & 27 \\
\hline Total & 37 & 100 \\
\hline Sumber: data primer, 2020 & &
\end{tabular}

Berdasarkan tabel 3.Diketahui sebagaian besar ibu hamil melakukan aktivitas sedang sejumlah 14 orang $(37,8 \%)$, aktivitas ringan sejumlah 13 orang $(35,1 \%)$, dan aktivitas berat sejumlah 10 orang $(27 \%)$. 


\section{Konstipasi Ibu Hamil}

Tabel 4. Distribusi Frekuensi Konstipasi Ibu Hamil

\begin{tabular}{lcc}
\hline Konstipasi & Frekuensi & Prosentase \\
\hline Konstipasi & 26 & 70,3 \\
Tidak Konstipasi & 11 & 29,7 \\
\hline Total & 37 & 100 \\
\hline Sumber: data primer, 2020 & &
\end{tabular}

Berdasarkan tabel 4.Diketahui sebagaian besar ibu hamil mengalami konstipasi sejumlah 26 orang $(70,3 \%)$.

\section{Tabulasi Silang Aktivitas Fisik Dengan Konstipasi Ibu Hamil.}

Tabel 5. Distribusi Tabulasi Silang Aktivitas Fisik Dengan Konstipasi Ibu Hamil

\begin{tabular}{|c|c|c|c|c|c|c|}
\hline \multirow{3}{*}{$\begin{array}{l}\text { Aktivitas } \\
\text { Fisik }\end{array}$} & \multicolumn{4}{|c|}{ Konstipasi Ibu Hamil } & \multirow{2}{*}{\multicolumn{2}{|c|}{ Total }} \\
\hline & \multicolumn{2}{|c|}{ Konstipasi } & \multicolumn{2}{|c|}{$\begin{array}{c}\text { Tidak } \\
\text { Konstipasi }\end{array}$} & & \\
\hline & $f$ & $\%$ & $\mathrm{~F}$ & $\%$ & $\mathrm{~F}$ & $\%$ \\
\hline Ringan & 13 & 100 & 0 & 0,0 & 13 & 100 \\
\hline Sedang & 13 & 92,9 & 1 & 7,1 & 14 & 100 \\
\hline Berat & 0 & 0,0 & 10 & 100 & 10 & 100 \\
\hline Total & 26 & 703 & 11 & 297 & 37 & 100 \\
\hline
\end{tabular}

Sumber: data primer, 2020

Berdasarkan tabel 5. Menunjukkan ibu hamil yang mengalami konstipasi lebih banyak melakukan aktivitas ringan sejumlah 13 orang (100\%, aktivitas fisik sedang sejumlah 13 orang $(92,9 \%)$ dibandingkan yang tidak konstipati pada aktivitas fisik berat sejumlah 10 orang $(100 \%)$, aktifitas fisik sedang sejumlah 1 orang $(7,1 \%)$. Hasil uji statistic korelasi sebagai berikut.

\begin{tabular}{|c|c|c|c|c|c|}
\hline \multicolumn{6}{|c|}{ Correlations } \\
\hline & & $\begin{array}{c}\text { Gravidaru } \\
\text { m }\end{array}$ & Umur & $\begin{array}{c}\text { Aktivita_ } \\
\text { Fisik }\end{array}$ & $\begin{array}{c}\text { Konstip } \\
\text { asi }\end{array}$ \\
\hline \multirow[t]{4}{*}{ Gravidarum } & Pearson & 1 & $.422^{* *}$ & $.354^{*}$ & -.030 \\
\hline & Correlation & & & & \\
\hline & Sig. (2-tailed) & & .009 & .032 & .862 \\
\hline & $\mathrm{N}$ & 37 & 37 & 37 & 37 \\
\hline \multirow[t]{4}{*}{ Umur } & Pearson & $.422^{* *}$ & 1 & $.833^{* *}$ & $.685^{* *}$ \\
\hline & Correlation & & & & \\
\hline & Sig. (2-tailed) & .009 & & .000 & .000 \\
\hline & N & 37 & 37 & 37 & 37 \\
\hline \multirow{4}{*}{$\begin{array}{l}\text { Aktivita_Fis } \\
\text { ik }\end{array}$} & Pearson & $.354^{*}$ & $.833^{* *}$ & 1 & $.821^{* *}$ \\
\hline & Correlation & & & & \\
\hline & Sig. (2-tailed) & .032 & .000 & & .000 \\
\hline & N & 37 & 37 & 37 & 37 \\
\hline \multirow[t]{4}{*}{ Konstipasi } & Pearson & -.030 & $.685^{* *}$ & $.821^{* *}$ & 1 \\
\hline & Correlation & & & & \\
\hline & Sig. (2-tailed) & .862 & .000 & .000 & \\
\hline & $\mathrm{N}$ & 37 & 37 & 37 & 37 \\
\hline
\end{tabular}

Sumber: data primer, 2020

Gambar 1. Hasil Uji Statistik Hubungan Aktivitas Fisik dengan Kejadian Konstipasi Pada Ibu Hamil

Berdasarkan hasil uji statistic korelasi antara aktivitas fisik dengan konstipasi ibu hamil nilai positif 0,821 menunjukkan sangat kuatnya korelasi hubungan antara aktivitas fisik dengan konstipasi significant (2-tailed) 0,00 $<0,01$ semakin tinggi aktivitas fisik ibu hamil maka makin tinggi terjadi konstipasi.

\section{PEMBAHASAN}

\section{Gambaran Umum Lokasi Penelitian}

Penelitian ini dilakukan di bidan Praktik Mandiri (BPM) Siti Mudlikah yang merupakan tempat milik peneliti sendiri, tempat ini berada ditengah-tengah Desa Kabupaten Wilayah Sidoarjo Yaitu Desa Jatikalang Kecamatan Prambon. Pelayanan kebidanan yang diberikan di BPM meliputi: Asuhan kehamilan, asuhan persalinan, asuhan ibu nifas, pelayanan keluarga berencana (KB), pelayanan kesehatan reproduksi, asuhan BBL, asuhan imunisasi, dan asuhan MTBS.

\section{Karakteristik Ibu hamil}

Berdasarkan Tabel 1. Menunjukkan karakteristik ibu hamil dari gravida dua 
sejumlah 24 orang $(64,9 \%)$ dan berusia $20-35$ tahun sejumlah 21 orang $(56,8 \%)$.

Faktor gravida menunjukkan konstipasi terbanyak terjadi pada ibu hamil dengan gravida dua dimana ibu hamil ini sudah memiliki pengalaman pada kehamilan sebelumnya. Dari hasil karateristik ibu hamil berdasarkan gravida menunjukkan bahwa ibu hamil yang mengalami konstipasi terbanyak pada ibu hamil gravida dua sehingga jumlah gravida tidak terkait dengan terjadinya konstipasi kehamilan. Maka konstipasi kehamilan dapat terjadi pada semua ibu hamil tanpa melihat latarbelakng jumlah kehamilan.

Faktor konstipasi berdasarkan usia 20-35 tahun merupakan masa usia produktif dimana horman dapat diproduksi dengan baik, peningkatan hormone progesterone masa usia produktif ini saat kehamilan menyebbakan otot polos usus besar mengalami penurunan peristaltic pada colon sehingga dapat terjadi konstipasi masa kehamilan. Sesuai penelitian sebelumnya bahwa sebagaian besar ibu hamil yang mengalami konstipasi lebih banyak pada multigravida dibanding prigravida dan konstipasi lebih banyak berusia 20-35 tahun (Heijnen et al., 2013).

Konstipasi sering dialami ibu hamil di karena beberapa faktor diantaranya karena adanya perubahan fisik kehamilan seperti pembesaran uterus yang menyebabkan colon dan rectum tertekan mempersulit ekskresi faeses. Konstipasi dapat terjadi kapan pun masa kehamilan baik trimester 1, II maupun trimester III. Menurut Ratih Indah Kartika (2017) menyatakan ada antara pregnancy exercises dengan konstipasi kehamilan trimester II. Dalam mencegah terjadinya konstipasi masa kehamilan tersebut dilakukan peningkatan penyuluhan tentang cara mencegah konstipasi dengan cara pregnancy exercise (Kartikasari \& Payana, 2017).

\section{Aktivitas Fisik Ibu Hamil}

Tabel 3 Menunjukkan aktivitas fisik sedang sejumlah 14 orang $(37,8 \%)$, aktivitas ringan sejumlah 13 orang $(35,1 \%)$, dan aktivitas berat sejumlah 10 orang (27\%).

Aktivitas fisik merupakan semua kegiatan yang dilakukan ibu hamil dalam seharihari baik aktivitas ringan hingga aktivitas berat, Aktifitas fisik dilakukan bertujuan untuk mempelancar peredaran darah, kebugaran dan juga mempengaruhi peristaltic otot polos pencernaan, karena keterbatasan aktifitas fisik dapat berdampak pada konstipasi kehamilan (Sibarani et al., 2020)

Penelitian sebelumnya berpendapat aktifitas fisik ringan dan sedang cenderung beresiko mengalami konstipasi dibandingkan dengan ibu hamil yang melakukan aktifitas berat. Hal ini karena kurangnya aktifitas meningkatkan resiko ibu hamil mengalami konstipasi. Aktifitas fisik rutin yang dilakukan ibu hmail dapat memicu gerak peristaltic otot usus sistem pencernaan hingga terjadi faeses pembuangan secara normal (Hartinah et al., 2019). Penelitian ini diperkuat oleh pendapat Maria dkk (2019) bahwa aktivitas fisik ringan memiliki hubungan dengan terjadinya konstipasi. Konstipasi berdampak pada timbulnya penyakit lain yaitu hemoroid, kanker colom, impaksi fektal dan hipertensi arterial (Sibarani et al., 2020).

Aktivitas fisik ibu hamil dalam penelitian ini dibagi 3 kategori sesuai kuesioner meliputi: 1) Aktifitas fisik ringan yaitu: menulis, membaca, membuat minuman dll, 2) Aktifitas fisik sedang yaitu: menyapu, mengepel, masak dll, 3) Aktifitas fisik berat yaitu: pekerjaan yang mengeluarkan banyak tenaga, mengangkat barang berat, petani, pekerja pabrik dll. Hasil temua ini diperkuat dengan pendapat dua penelitian tersebut diatas bahwa aktifitas fisik ringan dan aktifitas fisik sedang terbanyak menyebabkan konstipasi. Hal ini karena menurunya kerja peristaltik otot polos pada sistem pencernaan.

Ibu hamil yang kurang melakukan aktifitas fisik lebih besar berpotensi mengalami konstipasi, ibu yang malas melakukan imobilisasi akan menurunkan gerak peristaltic pencernaan 
sehingga penyerapan air pada usus besar mengalami peningkatan yang mengakibatkan faeses menjadi lebih keras dan sulit keluar.

Upaya yang dilakukan untuk mengurangi konstipasi pada ibu hamil meliputi: 1) Melakukan aktifitas fisik baik ringan dan sedang maupun berat minimal dilakukan dengan durasi waktu lebih dari 30 menit hal tersebut meningkatkan mobilitas peristaltic pada usus besar pencernaan, 2) melakukan senam hamil minimal 30 menit sehari secara rutin dan teratur, 3) melakukan gaya hidup sehat yaitu melakukan aktivitas jalan pagi hari untuk merangsang peristaltic usus besar, memperlancar sirkulasi peredaran darah dan juga memperoleh oksigen yang masih bersih yang dapat diabsorsi oleh seluruh tubuh ibu dan janin. Aktivitas tersebut merupakan cara untuk mencegah terjadinya konstipasi kehamilan.

\section{Konstipasi Ibu Hamil}

Berdasarkan tabel 4. Menunjukkan dari 37 ibu hamil yang mengalami konstipasi sejumlah 26 orang $(70,3 \%)$ dan tidak kontipasi sejumlah 11 orang $(29,7 \%)$. Hasil penelitian ini sebagaian besar ibu hamil yang mengalami konstipasi pada gravidarum dua dan berusia 20 35 tahun.

Konstipasi kehamilan adalah kondisi dimana ibu hamil mengalami kesulitan buang faeses (kurnag dari tiga kali dalam seminggu). Gejala konstipasi yang rasakan ibu hamil seperti: perut kembung, nyeri perut bawah dan kesulitan buang faeses (Ojieh, 2012). Absorsi cairan berlebihan menurunkan pergerakan usus halus menyebabkan lambatnya faeses sehingga terkumpul pada colon desenden dengan jumlah banyak dan kering

Faktor-faktor yang mempengaruhi kontipasi meliputi: 1) adanya peningkatan hormone progresteron dan estrogen kehamilan, 2) efek pemberian $\mathrm{Fe}$ beresiko terjadi konstipasi, 3) pola makan diet tinggi serat dan cairan cukup bu hamil juga berperan penting mempengaruhi konsistensi faeses dimana ibu hamil yang kurang mengkonsumsi asupan nutrisi berserat dan kekurangan cairan beresiko terjadi konstipasi, 4) Posisi defekasi yaitu posisi jongkok yang memudahkan defesikasi dan posisi duduk membuat rectum mengedam lebih kuat (Sembiring, 2017). Namun faktor ini berbeda dengan penelitian ini bahwa asupan serat tinggi dan kecukupan cairan tidak berkaitan dengan terjadinya konstipasi pada ibu hami (Muawanah \& Nindya, 2017).

Faktor hormone masa kehamilan yaitu adanya peningkatan hormone progesterone juga dapat mempengaruhi terjadinya konstipasi, dimana gerak peristaltik usus besar menurun dan mengakibatkan tertahannya tinja (faeses) didalam usus besar sehingga sulit untuk dikeluarkan. Konstipasi sering terjadi pada ibu hamil trimester satu dan tiga disebabkan karena tingginya tingkat hormone pada periode tersebut sehingga memperlambat kerja otot polos pada percernaan (Trottier et al., 2012)

Berdasarkan Tabel 5. Menunjukkan ibu hamil yang mengalami konstipasi lebih banyak melakukan aktivitas ringan sejumlah 13 orang (100\%, aktivitas fisik sedang sejumlah 13 orang $(92,9 \%)$ dibandingkan yang tidak konstipati pada aktivitas fisik berat sejumlah 10 orang $(100 \%)$, aktifitas fisik sedang sejumlah 1 orang $(7,1 \%)$. Hasil uji statistic korelasi antara aktivitas fisik dengan konstipasi ibu hamil nilai positif 0,821 menunjukkan sangat kuatnya korelasi hubungan antara aktivitas fisik dengan konstipasi significant (2-tailed) $0,00<0,01$ semakin tinggi aktivitas fisik ibu hamil maka makin tinggi terjadi konstipasi.

Hasil penelitian ini menunjukkan bahwa aktivitas fisik ringan dan sedang yang tidak rutin dan tidak teratur serta kurang dari 30 menit sehari berpotensi terjadi konstipasi pada ibu hamil, kurangnya mobilisasi peristaltic usus besar akibat adanya pembesaran uterus, peningkatan hormone progresteros masa kehamilan sebagai pemicu penyebab konstipasi masa kehamilan, terbukti pada hasil penelitian ini bahwa ibu hamil yang melakukan aktifitas berat lebih jarang terjadi konstipasi masa kehamilan. Aktifitas fisik berat ini yang dilakukan ibu hamil seperti: mencuci, memasak, 
menyapu yang secara berturut lebih dari 30 menit, bekerja di sawah menanam sayur, menyiram sayur dan memupuk sayur yang bergerak lebih dari 30 menit.

Penelitian ini diperkuat hasil penelitian sebelumnya bahwa aktifitas fisik yang dilakukan rutin dan cukup seperti olahraga kurang dari 30 menit akan merangsang motilitas pencernaan usus dan peristaltik massa faeces. Ibu hamil usia lebih dari 35 tahun semakin malas bergerak sehingga gerak periltaltik usus makin lambat(Hanim, 2019). Faktor lain juga berpengaruh terjadinya konstipasi seperti makan pisang sebelum makan, minum air mineral cukup (Indah \& Rohmania, 2017).

Analisis hasil uji korelasi menunjukkan nilai signifikan yang sangat kuat terdapat hubungan antara aktifitas fisik dengan konstipasi masa kehamilan. Dimana aktifitas fisik ringan dan aktifitas fisik sedang yang kurang dari durasi waktu 30 menit dan tidak teratur sangat berpontensi terjadi konstipasi pada ibu hamil terutama pada trimester tiga. Selain aktivitas fisik ibu hamil, konstpasi juga dipengaruhi beberapa faktor lainnya seperti: asupan nutrisi yang kurang serat dan kurang konsumsi air mineral yang kurang maupun faktor lainnya juga berpotensi lebih untuk terjadi konstipasi kehamilan.

Upaya yang dilakukan oleh tenaga kesehatan untuk mencegah hal tersebut harus memperhatikan banyak aspek yang kemungkinan setiap ibu hamil dapat terjadi kontipasi sehingga dapat dilakukan upaya pencegahan konstipasi dengan cara melakukan penyuluhan dan pendidikan kesehatan pada ibu hamil trimester awal yaitu trimester satu, melakukan penyuluhan tentang asupan nutrisi diet tinggi serat dan minum air mineral cukup, melakukan mobilisasi aktifitas fisik ringan dan sedang dengan rutin,minimal waktu 30 menit, melakukan kebiasaan tidak menundah buang air besar dan posisi jongkok untuk memudahkan buang air besar.

\section{SIMPULAN}

Simpulan hasil penelitian ini yaitu sebagaian besar ibu hamil melakukan aktivitas fisik ringan dan sedang mengalami konstipasi dibandingkan dengan ibu hamil yang jarang mengalami konstipasi pada aktivitas berat. Dan adanya hubungan yang sangat kuat antara aktivitas fisik ibu hamil dengan konstipasi.

Aktifitas fisik ringan dan aktivitas fisik sedang tersebut dilakukan ibu hamil kurang dari 30 menit dan tidak dilakukan secara rutin kemungkinan sebagai salah satu penyebab terjadinya konsipasi kehamilan. Pencegahan konstipasi dapat dilakukan dengan melakukan mobilisasi aktifitas fisik secara teratur dan rutin lebih dari 30 menit sehari maupun melakukan senam hamil secara teratur dan rutin dapat merangsang gerak otot besar memperlancar pembuangan faeses. upaya lain seperti diet asupan nutrisi tinggi serat pada sayur dan buah serta minum air mineral cukup juga mencegah terjadi kontipasi pada ibu hamil.

\section{UCAPAN TERIMA KASIH}

Terima kasih saya ucapkan pada semua pihak yang ikut berpartisipasi terkait dengan penelitian ini khususnya ibu hamil yang telah bersedia bekerjasama dalam penelitian ini

\section{DAFTAR PUSTAKA}

Hanim, B. (2019). Analisis Penyebab Konstipasi Pada Ibu Hamil Di Wilayah Kerja Puskesmas Payung Sekaki Pekanbaru. Health Care: Jurnal Kesehatan, 8(1), 7076.

https://doi.org/10.36763/healthcare.v8i 1.51

Hartinah, D., Karyati, S., \& Rokhani, S. (2019). Hubungan Pola Aktivitas Fisik Dengan Konstipasi Pada Ibu Hamil Trimester lii Di Puskesmas Gribig Kecamatan Gebog Kabupaten Kudus Tahun 2017. Jurnal IImu Keperawatan Dan Kebidanan, 10(2), 350. https://doi.org/10.26751/jikk.v10i2.651 
Heijnen, J. H., Jussi Hanhimaki, Steiner, A., Abiko, T., Obara, M., Ushioda, A., Hayakawa, T., Hodges, M., Yamaya, T., Snidal, D., Dissertation, B. A., In, S., Of, F., Requirements, T. H. E., The, F. O. R., Of, A. A., Doctor, T. H. E., ... Hinsley, F. . (2013). No Title SSRN Electronic Journal, 1(2), 99-117.

http://www.eldis.org/vfile/upload/1/do cument/0708/DOC23587.pdf\%0Ahttp://so cserv2.socsci.mcmaster.ca/ econ/ugcm/ 31l3/michels/polipart.pdf\%0Ahttps://ww w.theatlantic.com/magazine/archive/199 4/02/the-cominganarchy/304670/\%0Ahttps: //scholar.goog le.it/scholar?

Indah, S., \& Rohmania, anis zuni. (2017). Pengaruh Konsumsi Buah Pisang raja, minum air mineral dan jalan pagi terhadap kejadian konstipasi pada ibu hamil trimester III di BPS Sunarsih Yudhawati. Jurnal Kebidanan, 5, 13-17. file:///C:/Users/LRNOVO/Downloads/848 -2944-1-PB (1).pdf

Kartikasari, R. indah, \& Payana, S. H. dwi. (2017). Pregnancy Exercises Dengan Kejadian Konstipasi Pada Ibu Hamil Trimester II. Surya, 09(01), 54-60.

Muawanah, M., \& Nindya, T. S. (2017). Hubungan Asupan Serat Dan Cairan Dengan Kejadian Konstipasi Pada Ibu Pasca Melahirkan. Media Gizi Indonesia, 11(1), 101.

https://doi.org/10.20473/mgi.v11i1.101105

Ojieh, A. E. (2012). Constipation in pregnancy and the effect of vegetable consumption in different socio - economic class in warri, delta state. Journal of Medical and Applied Biosciences, 4(June), 1-6. https://www.cenresinjournals.com/wpcontent/uploads/2020/02/page-1-6743.pdf

Preventing or Treating Constipation in. (2008). July 2007, 1-15.
Sembiring, L. P. (2017). Konstipasi pada Kehamilan. Jurnal Ilmu Kedokteran, 9(1), 7.

https://doi.org/10.26891/jik.v9i1.2015.710

Sibarani, M. V., Ulfah, R., \& Afriyanti, E. (2020). Hubungan Aktivitas Fisik Terhadap Konstipasi pada Pasien Stroke di RS Islam Siti Rahmah Padang. Jurnal Kesehatan Andalas, $\quad$ 8(4), 134-137. https://doi.org/10.25077/jka.v8i4.1130

Trottier, M., Erebara, A., \& Bozzo, P. (2012). Treating constipation during pregnancy. Canadian Family Physician, 58(8), 836.

Widyasari, S. (2017). Upaya Penanganan Masalah Konstipasi Ibu Hamil Trimester III. 1-15.

http: / /eprints.ums.ac.id/52351/4/KTI SUDAH JADI VERSI PERPUSTAKAAN.pdf 